\title{
Carbon-13 Relaxation of Methyl Derivatives of Polystyrene in Solution
}

\author{
Tadashi OKADA \\ Central Research Laboratory, Toyo Soda Manufacturing Co., Ltd., \\ 4560, Tonda, Shinnanyo-shi, Yamaguchi-ken, Japan.
}

(Received March 12, 1979)

\begin{abstract}
Carbon-13 spin-lattice relaxation times and line-widths have been measured for solutions of $o-, m$-, and $p$-methyl derivatives of polystyrene at temperatures ranging between 30 and $60^{\circ} \mathrm{C}$. Spin-lattice relaxation times of these polymers are intimately related with molecular motions, namely, the segmental motion and two internal motions of the phenyl and methyl groups. With respect to the internal rotation of the phenyl group, a transition change was observed in the vicinity of $50^{\circ} \mathrm{C}$ for poly $(o$-methylstyrene $), 45^{\circ} \mathrm{C}$ for poly $\left(m\right.$-methylstyrene) and $40^{\circ} \mathrm{C}$ for poly $(p$-methylstyrene), respectively. In comparison with the model of a freely rotating methyl group, it is concluded that the mobility of the methyl group decreases from the para to the ortho position of the substituent. This result suggests that the trend of the steric hindrance between the hydrogens bonded to the methyl carbon and those in the backbone has an effect on the segmental motion and the rotation of the phenyl group. The finding that the activation energies for the segmental motion and the rotation of the phenyl group in poly $(m$-methylstyrene $)$ were larger than those in poly $(o-$ methylstyrene) and smaller than those in poly(p-methylstyrene) is in accord with the above suggestion.
\end{abstract}

KEY WORDS Methyl Derivatives of Polystyrene $/{ }^{13} \mathrm{C}-\mathrm{NMR} /$ Spin-Lattice

Relaxation / Internal Rotation / Transition / Line-Width / Correlation Time /

In polystyrene and its derivatives, the rotational transition of the phenyl group has been investigated at several laboratories. ${ }^{1-4}$ Bach Van et al. measured the temperature dependency of the UV molar extinction coefficients of dilute solutions of polystyrene and its derivatives, and the transitional anomalies for the rotation of the phenyl groups of the methyl substituted polystyrenes were obtained at temperatures ranging from 30 to $80^{\circ} \mathrm{C}^{2}$

Recently, Lanpretre et al. compared the intramolecular mobility of halogenated and methylated polystyrenes with that of polystyrene in solution, using the results of measurements of ${ }^{13} \mathrm{C}$ spin-lattice relaxation times, but no information of the rotational transitions of the phenyl groups could obtain since these relaxation time measurements were carried out at $30^{\circ} \mathrm{C} .^{5}$

This paper reports the temperature dependences of ${ }^{13} \mathrm{C}$ spin-lattice relaxation times and line-widths for individual carbons of monomer units in methyl derivatives of polystyrene in $\mathrm{CDCl}_{3}$ solution, the rotational transitions of the phenyl groups and the steric hindrance effect of the methyl groups.

\section{EXPERIMENTAL}

\section{Samples}

Polymerizations of $o$-methylstyrene, $m$-methylstyrene and $p$-methylstyrene, obtained from Tokyo Kasei Co., Ltd., were initiated by butyllithium in benzene at $25^{\circ} \mathrm{C}$. The number average molecular weights for poly $(o$-methylstyrene $) \quad(\mathrm{P}(o-\mathrm{MS}))$, $\operatorname{poly}(m$-methylstyrene $) \quad(\mathrm{P}(m-\mathrm{MS}))$ and $\operatorname{poly}(p-$ methylstyrene) (P(p-MS)), measured by GPC, were $2.0 \times 10^{4}, 1.0 \times 10^{4}$, and $2.3 \times 10^{4}$, respectively.

\section{Methods}

${ }^{13} \mathrm{C}$-NMR spectra were recorded at $25.05 \mathrm{MHz}$ using a JEOL FX-100 spectrometer equipped with an internal ${ }^{2} \mathrm{D}$ lock and a noise modulated ${ }^{1} \mathrm{H}$ decoupler. The $90^{\circ}$ pulse width was about $15 \mu \mathrm{s}$, and its recycle time was chosen as $10 \mathrm{~s}$. The samples were prepared as $20 \%(\mathrm{w} / \mathrm{v}) \mathrm{CDCl}_{3}$ solutions in eggshaped microcells, which were inserted in $10 \mathrm{~mm}$ O.D. glass tubes. The normal proton-decoupled ${ }^{13} \mathrm{C}$ NMR spectra of $\mathrm{P}(o-\mathrm{MS}), \mathrm{P}(m-\mathrm{MS})$ and $\mathrm{P}(p-\mathrm{MS})$ are shown in Figure 1. The values of the chemical 


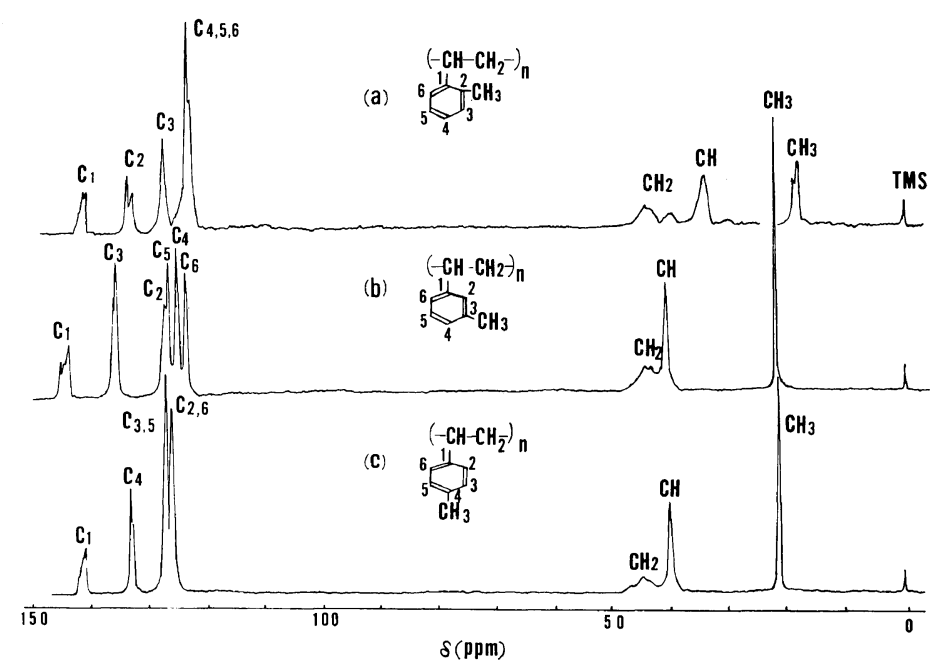

Figure 1. ${ }^{1} \mathrm{H}$-decoupled ${ }^{13}$-C-NMR spectra of $20 \%(\mathrm{w} / \mathrm{v})$ methyl derivatives of polystyrene in $\mathrm{CDCl}_{3}$ at $25.05 \mathrm{MHz}$ and $30^{\circ} \mathrm{C}$. Each spectrum is the result of 500 accumulations with a recycle time of $10 \mathrm{~s}:$ (a) $\mathrm{P}(o-$ MS); (b) P(m-MS); (c) P(p-MS).

shift of the spectral lines in Figure 1 are in a good agreement with those measured by Evans, et al. ${ }^{6}$

Nuclear Overhauser enhancement values were determined from peak areas obtained initially with complete proton decoupling and finally with the decoupling unit suppressed. The latter was obtained by using pulse-modulated proton decoupling which involves gating the decoupler "on" during data aquisition and "off" during the remaining time.

Spin-lattice relaxation time $\left(T_{1}\right)$ for each carbon was determined from proton-decoupled partially relaxed Fourier transform (PRFT) spectra obtained by $\left(180^{\circ}-t-90^{\circ}\right)_{n}$ pulse sequences. The intensities measured from a set of PRFT spectra were used to determine $T_{1}$, according to the equation,

$$
M(t)=M_{0}\left[1-2 \exp \left(-t / T_{1}\right)\right]
$$

were $M_{0}$ is the equillibrium intensity in a normal FT spectrum measured with delayed time $t$.

\section{RESULTS AND DISCUSSION}

\section{Nuclear Overhauser Enhancement}

For the case of ${ }^{13} \mathrm{C}$ nuclei under conditions of proton-decoupling, the nuclear Overhauser enhancement $(N O E)$ is given by, ${ }^{7}$

$$
N O E=1+\frac{\gamma_{\mathrm{H}}}{\gamma_{\mathrm{C}} \chi}\left[\frac{6 \tau_{\mathrm{C}}}{1+\left(\omega_{\mathrm{H}}+\omega_{\mathrm{C}}\right)^{2} \tau_{\mathrm{C}}^{2}}\right.
$$

$$
\left.-\frac{\tau_{\mathrm{C}}}{1+\left(\omega_{\mathrm{H}}-\omega_{\mathrm{C}}\right)^{2} \tau_{\mathrm{C}}^{2}}\right]
$$

where

$$
\begin{aligned}
\chi=\frac{\tau_{\mathrm{C}}}{1+\left(\omega_{\mathrm{H}}-\omega_{\mathrm{C}}\right)^{2} \tau_{\mathrm{C}}{ }^{2}} & +\frac{3 \tau_{\mathrm{C}}}{1+\omega_{\mathrm{C}}{ }^{2} \tau_{\mathrm{C}}{ }^{2}} \\
& +\frac{6 \tau_{\mathrm{C}}}{1+\left(\omega_{\mathrm{H}}+\omega_{\mathrm{C}}\right)^{2} \tau_{\mathrm{C}}{ }^{2}}
\end{aligned}
$$

In the extreme narrowing limit, eq 2 reduces to the well-known expression,

$$
N O E=1+\frac{\gamma_{\mathrm{H}}}{2 \gamma_{\mathrm{C}}}=1+\eta=2.987
$$

Table I lists the NOE factor $(1+\eta)$ for each carbon of the methyl substituted polystyrenes. The NOE values obtained at $70^{\circ} \mathrm{C}$ in Table I are smaller than the theoretical maximum of 2.987. Similar discrepancies have already been obtained by Schaefer and Natusch for several polymer relaxations with by a purely dipolar ${ }^{13} \mathrm{C}-{ }^{1} \mathrm{H}$ mechanism, ${ }^{8}$ and they suggested that the unknown correlation function describing the actual motion may not differ greatly from that due to isotropic motion described by a single average correlation time.

In Table I, the NOE value for the methyl carbon in 
Table I. NOE of methyl derivatives of polystyrene

\begin{tabular}{|c|c|c|}
\hline \multirow{2}{*}{ Line } & \multicolumn{2}{|c|}{$N O E(1+\eta)$} \\
\hline & $70^{\circ} \mathrm{C}$ & $40^{\circ} \mathrm{C}$ \\
\hline \multicolumn{3}{|l|}{$\mathrm{P}(o-\mathrm{MS})$} \\
\hline \multicolumn{3}{|l|}{ Ring-carbon } \\
\hline Substituted $(1,2)$ & $2.3 \pm 0.2$ & \\
\hline Unsubstituted (3) & $2.4 \pm 0.2$ & \\
\hline$(4,5,6)$ & $2.5 \pm 0.2$ & \\
\hline$\alpha$-carbon & $2.6 \pm 0.2$ & \\
\hline Methyl-carbon & $2.7 \pm 0.3$ & \\
\hline \multicolumn{3}{|l|}{$\mathrm{P}(m-\mathrm{MS})$} \\
\hline \multicolumn{3}{|l|}{ Ring-carbon } \\
\hline Substituted $(1,3)$ & $2.5 \pm 0.2$ & \\
\hline Unsubstituted (4) & $2.7 \pm 0.3$ & \\
\hline$(6)$ & $2.7 \pm 0.3$ & \\
\hline$\alpha$-carbon & $2.7 \pm 0.3$ & \\
\hline Methyl-carbon & $2.5 \pm 0.2$ & \\
\hline \multicolumn{3}{|l|}{$\mathrm{P}(p-\mathrm{MS})$} \\
\hline \multicolumn{3}{|l|}{ Ring-carbon } \\
\hline Substituted $(1,4)$ & $2.3 \pm 0.2$ & $2.3 \pm 0.2$ \\
\hline Unsubstituted $(3,5)$ & $2.6 \pm 0.2$ & $2.4 \pm 0.2$ \\
\hline$(2,6)$ & $2.6 \pm 0.2$ & $2.4 \pm 0.2$ \\
\hline$\alpha$-carbon & $2.7 \pm 0.3$ & $2.3 \pm 0.2$ \\
\hline Methyl-carbon & $2.3 \pm 0.2$ & $2.2 \pm 0.2$ \\
\hline
\end{tabular}

$\mathrm{P}(p-\mathrm{MS})$ is smaller than those for $\mathbf{P}(m-\mathrm{MS})$ and $\mathbf{P}(o-$ MS). This evidence demonstrates that the relaxation mechanism of a freely rotating methyl carbon in $\mathrm{P}(p-$ MS), as stated in correlation time, has substantial contributions from spin-rotation effects. ${ }^{9}$ If the relaxation mechanism of the methyl carbon in $\mathrm{P}(p-$ MS) is attributed to both the dipole-dipole and spinrotation interaction, the relationship of the relaxation times due to the former and the latter is given by ${ }^{9}$

$$
\frac{T_{1}(S P)}{T_{1}(D D)}=\frac{\eta}{1.987-\eta}
$$

where $T_{1}(D D)$ and $T_{1}(S P)$ are the relaxation times due to the dipole-dipole and the spin-rotation interaction, respectively. In $\mathrm{P}(p$-MS $), T_{1}(S P)$ $T_{1}(D D) \simeq 1.9$ from $\eta=1.3$ in Table $\mathrm{I}$.

\section{Line-Width}

Since Bach Van et al. ${ }^{2}$ demonstrated a transitional change for the rotation of the phenyl group of the methyl derivatives of polystyrene in the temperature range from 30 to $70^{\circ} \mathrm{C}$, it is of interest to measure the line-width $\left(\Delta H_{1 / 2}\right)$ within this tempera-

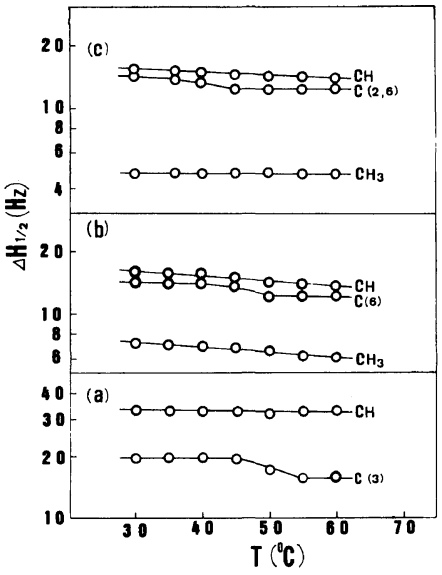

Figure 2. A semilog plot of the line-widths deduced from normal spectra as a function of temperature: (a) $\mathrm{P}(o-\mathrm{MS})$; (b) $\mathrm{P}(m-\mathrm{MS})$; (c) $\mathrm{P}(p-\mathrm{MS})$.

ture range. From the temperature dependence of $\Delta H_{1 / 2} \mathrm{~s}$ in Figure 2, transition phenomena are observed for protonated ring carbons; the transition occurs at about $40^{\circ} \mathrm{C}$ for $\mathrm{P}(p-\mathrm{MS}), 45^{\circ} \mathrm{C}$ for $\mathrm{P}(m-\mathrm{MS})$ and $50^{\circ} \mathrm{C}$ for $\mathrm{P}(o-\mathrm{MS})$.

\section{Spin-Lattice Relaxation Times}

The temperature dependences of $T_{1} \mathrm{~s}$ for the carbons in $\mathrm{P}(o-\mathrm{MS}), \mathrm{P}(m-\mathrm{MS})$, and $\mathrm{P}(p-\mathrm{MS})$ are shown in Figure 3, 4, and 5, respectively. The signal for the methyl carbon of $\mathrm{P}(o-\mathrm{MS})$ splits into two peaks owing to the effect of tacticity as shown in Figure 1, and the temperature dependence of these $T_{1} \mathrm{~s}$ is presented in Figure 3. In Figure 3, 4, and 5, each $T_{1}$ for the methine carbon $(\mathrm{C}(\alpha))$ and the methyl carbon increases linearly with temperature, while

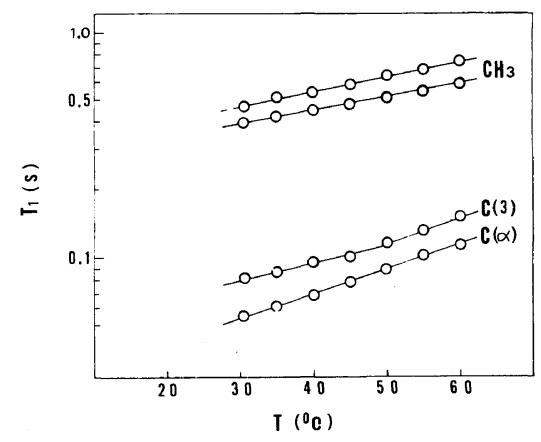

Figure 3. A semilog plot of the spin-lattice relaxation times for the carbons of $\mathrm{P}(o-\mathrm{MS})$ as a function of temperature. 


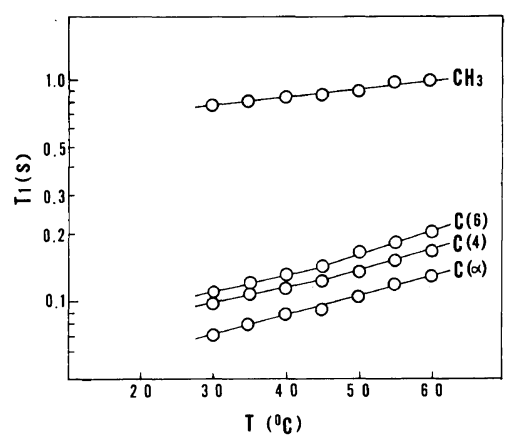

Figure 4. A semilog plot of the spin-lattice relaxation times for the carbons of $\mathrm{P}(m-\mathrm{MS})$ as a function of temperature.

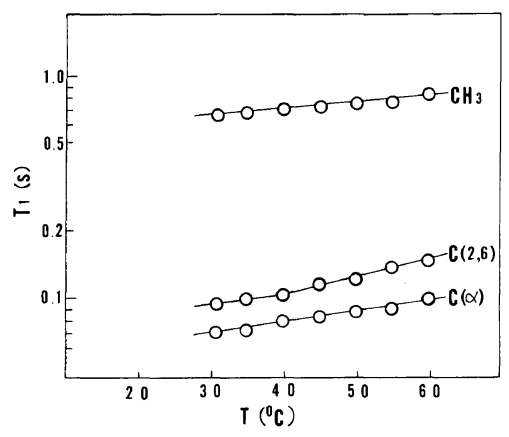

Figure 5. A semilog plot of the spin-lattice relaxation times for the carbons of $\mathrm{P}(p-\mathrm{MS})$ as a function of temperature.

those for the protonated ring carbon do not.

\section{Correlation Time}

Assuming purely intramolecular interaction between ${ }^{13} \mathrm{C}$ and ${ }^{1} \mathrm{H}, T_{1}$ can be approximated by, ${ }^{10}$

$$
\begin{aligned}
\frac{1}{T_{1}}= & \frac{1}{10} \hbar^{2} \gamma_{\mathrm{C}}^{2} \gamma_{\mathrm{H}}^{2} \sum_{i} r_{i}^{-6}\left[f\left(\omega_{\mathrm{H}}-\omega_{\mathrm{C}}\right)+3 f\left(\omega_{\mathrm{C}}\right)\right. \\
& \left.+6 f\left(\omega_{\mathrm{H}}+\omega_{\mathrm{C}}\right)\right]
\end{aligned}
$$

where

$$
f(\omega)=\tau_{\mathbf{R}}\left(1+\omega^{2} \tau_{\mathrm{R}}^{2}\right)^{-1}
$$

and $\tau_{\mathrm{R}}$ is the single rotational correlation time for ${ }^{13} \mathrm{C}-{ }^{1} \mathrm{H}$ coupling, and $r_{i}$ is the distance between the $i$ th proton and the ${ }^{13} \mathrm{C}$ uncleus in question. In the extreme narrowing limit, eq 6 yields the well-known expression:

$$
\frac{1}{T_{1}}=\hbar^{2} \gamma_{\mathrm{C}}^{2} \gamma_{\mathrm{H}}^{2} \sum_{i} r_{i}^{-6} \tau_{\mathrm{R}}
$$

For a group bonded to a backbone undergoing isotropic reorientation, the dipolar relaxation rate $\left(1 / R_{1}(I)\right)$ is given by the following equation, ${ }^{10}$

$$
\frac{1}{T_{1}(I)}=\hbar 2 \gamma_{\mathrm{C}}^{2} \gamma_{2 \mathrm{H}}^{2} \sum_{i} r_{i}^{-6} \chi \tau_{\mathrm{R}}
$$

where $\tau_{R}$ is the single correlation time for the backbone carbon and,

$$
\begin{aligned}
\chi=\frac{1}{4}\left(3 \cos ^{2} \theta-1\right)^{2} & +18(5+\rho)^{-1} \sin ^{2} \theta \cos ^{2} \theta \\
+ & \frac{9}{4}(1+2 \rho)^{-1} \sin ^{4} \theta
\end{aligned}
$$

The expressions in eq 10 are defined as follows.

$$
\begin{aligned}
& \rho=\frac{D_{/ /}}{D_{\perp}} \\
& D_{\perp}=\left(6 \tau_{\mathrm{R}}\right)^{-1} \\
& D_{/ /} \equiv\left(6 \tau_{\mathrm{R}}\right)^{-1}+(6 \tau \mathrm{G})^{-1}
\end{aligned}
$$

$\tau_{\mathrm{G}}$ is the correlation time for a group rotation, and $D_{/ /}$and $D^{\perp}$ represent the diffusion constants for rotational diffusion parallel and perpendicular to the axis for internal motion, respectively, and $\theta$ is the angle between the axis for internal rotation and the $\mathrm{C}-\mathrm{H}$ bond vector.

Assuming a purely ${ }^{13} \mathrm{C}-{ }^{1} \mathrm{H}$ dipolar relaxation mechanism, which has been confirmed by Schaefer and Natusch ${ }^{8}$ for several polymers, $\tau_{R}$ and $\tau_{G}$ can be estimated from eq9-13. Rotation around the $\mathrm{C}(\alpha)-\mathrm{C}(1)$ axis leads to relaxation for the ortho and meta carbons since the $\mathrm{C}-\mathrm{H}$ bonds in these instances make angles $(\theta)$ of 60 and $120^{\circ}$ with the rotation axis. In the case of $T_{1} \mathrm{~s}$ for the protonated ortho and meta carbons, eq 9 is reduced to

$$
\frac{1}{T_{1}(I)}=\frac{1}{64 T_{1}(R)}\left(1+\frac{216}{6+K}+\frac{81}{3+2 K}\right)
$$

where $K=\tau_{\mathrm{R}} / \tau_{\mathrm{G}}$, and $T_{1}(\mathrm{R})$ is the relaxation time of backbone carbons.

Figure 6 shows an expanded view for estimating the rotational ratios of $\tau_{\mathrm{R}} / \tau_{\mathrm{G}}$ from $64 T_{1}(\mathrm{R}) / T_{1}(I)$ in the methyl substituted polystyrenes. The values of $\tau_{R}$ 
Carbon-13 Relaxation of Methyl Derivatives of Polystyrene in Solution

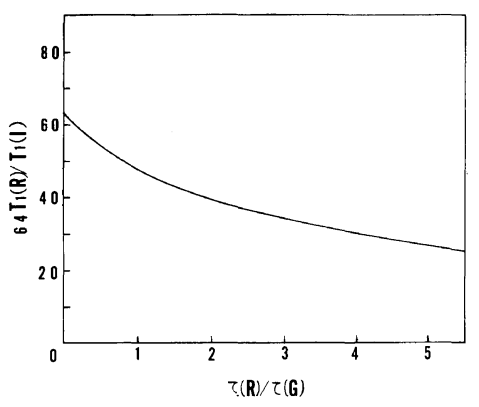

Figure 6. A plot of $64 T_{1}(R) / T_{1}(G)$ as a function of $\tau(R) / \tau(G)$.

are calculated by substitution of the observed $T_{1}(R) \mathrm{s}$ in eq 7 , while the values of $\tau_{\mathrm{G}}$ can be estimated readily from Figure 6 when the values of $T_{1}(R)$ and $T_{1}(I)$ are measured at the same temperature. If the methyl rotation is much faster than the backbone and ring reorientations, then eq 10 reduces to ${ }^{10}$

$$
\chi=\left(\frac{3}{2} \cos ^{2} \theta-\frac{1}{2}\right)^{2}
$$

Under this limiting condition, the carbon of a rapidly rotating methyl group $\left(\theta=109^{\circ}\right)$ relaxes 9 times more slowly than in absence of internal rotation.

Figure 7 shows the observed $T_{1}$ for a methyl carbon compared with 9 times $T_{1}$ for $\mathrm{C}(\alpha)$ under the limiting condition described above for $\mathrm{P}(o-\mathrm{MS})$,

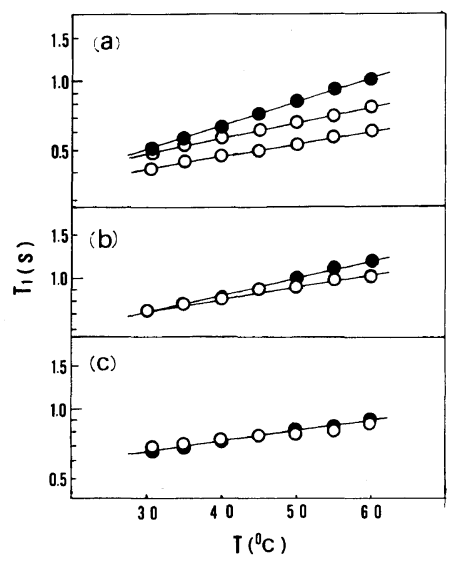

Figure 7. A semilog plot of the spin-lattice relaxation times for the methyl carbon of methyl derivatives of polystyrene as a function of temperature: (a) $\mathrm{P}(o-\mathrm{MS})$; (b) $\mathrm{P}(m-\mathrm{MS})$; (c) $\mathrm{P}(p-\mathrm{MS})$. (○) $T_{1}\left(\mathrm{CH}_{3}\right) ;(\bigcirc) 9 T_{1}(\mathrm{C}(\alpha))$.
$\mathrm{P}(m-\mathrm{MS})$ and $\mathrm{P}(p-\mathrm{MS})$, within a temperature range from 30 to $60^{\circ} \mathrm{C}$.

Consequently, the trend of the discrepancy between the former and the latter is $\mathrm{P}(o-\mathrm{MS})>\mathrm{P}(m$ MS $)>\mathrm{P}(p-\mathrm{MS})$, and the result for $\mathrm{P}(p-\mathrm{MS})$ suggests that the methyl group rotates freely about a three fold axis.

\section{Activation Energy}

Figure 8 shows the temperature dependences of the correlation times, $\tau(R)$ and $\tau(G)$. The values of $\tau(R)$ were calculated from $T_{1} \mathrm{~s}$ for $\alpha$-carbon by using eq 8 , while those of $\tau(G)$ on $\mathrm{P}(o-\mathrm{MS}), \mathrm{P}(m-\mathrm{MS})$ and

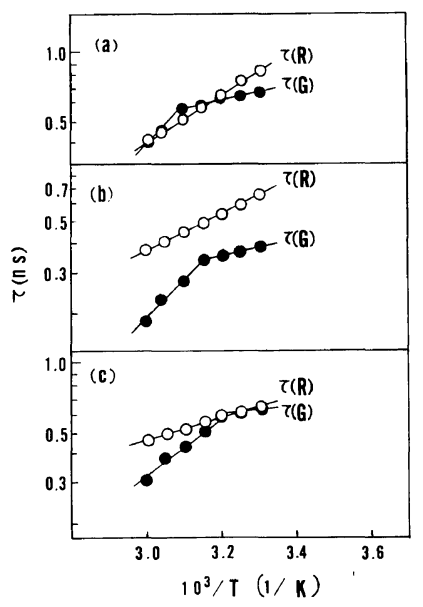

Figure 8. Arrhenius plot of the correlation times for the molecular motions as a function of $10^{3} / T$ ( $T$ being the absolute temp): (a) $\mathrm{P}(o-\mathrm{MS})$ (b) $\mathrm{P}(m$-MS); (c) $\mathrm{P}(p$-MS).

Table II. Activation energy for molecular motion of methyl derivatives of polystyrene in $20 \%(\mathrm{w} / \mathrm{v})$ solution in $\mathrm{CDCl}_{3}$

\begin{tabular}{lccc}
\hline \multirow{2}{*}{ Sample } & \multicolumn{3}{c}{$\Delta E / \mathrm{kcal} \mathrm{mol}^{-1} \mathrm{a}$} \\
\cline { 2 - 4 } & $R /$ motion & \multicolumn{2}{c}{$G /$ motion } \\
\cline { 2 - 4 } & & $\begin{array}{c}\text { Lower }^{\mathrm{b}} \\
\text { temperature } \\
\text { region }\end{array}$ & $\begin{array}{c}\text { Higher } \\
\text { temperature } \\
\text { region }\end{array}$ \\
$\mathrm{nyyy} \mathrm{P}(o$-MS $)$ & 4.7 & 1.7 & 7.6 \\
$\mathrm{P}(m$-MS $)$ & 3.4 & 1.6 & 7.2 \\
$\mathrm{P}(p$-MS $)$ & 2.3 & 0.7 & 6.3 \\
\hline
\end{tabular}

a $1 \mathrm{kcal} \mathrm{mol}^{-1}=4.184 \mathrm{~kJ} \mathrm{~mol}^{-1}$.

b From the transition temperature. 
$\mathrm{P}\left(p\right.$-MS) were calculated from $T_{1}$ s for $\mathrm{C}(3), \mathrm{C}(6)$ and $\mathrm{C}(2,6)$, respectively, by using eq 14 . In Figure 8 , it can be seen that the Arrhenius plots of $\tau(R)$ for the three compounds fall on the straight lines, and those of $\tau(G)$ show a break in the vicinity at $50^{\circ} \mathrm{C}$ for $\mathrm{P}(c$ $\mathrm{MS}), 45^{\circ} \mathrm{C}$ for $\mathrm{P}(m-\mathrm{MS})$, and $40^{\circ} \mathrm{C}$ for $\mathrm{P}(p$-MS $)$, respectively. The activation energy $(\Delta E)$ for each motion can be estimated by the following equation

$$
\tau=\tau_{\mathrm{o}} \exp (\Delta E / R T)
$$

where $\tau_{0}$ is the correlation time at infinite temperature and $R$ is the gas constant.

Table II presents the activation energies for each motion of $\mathrm{P}(o-\mathrm{MS}), \mathrm{P}(m-\mathrm{MS})$ and $\mathrm{P}(p$-MS $)$. The $\Delta E$ for the segmental motion of $\mathrm{P}(p-\mathrm{MS})$ is in good agreement with that for the atactic polystyrene of $2.5 \mathrm{kcal} \mathrm{mol}^{-3}\left(10.5 \mathrm{~kJ} \mathrm{~mol}^{-3}\right)$ within an experimental error of $\pm 10 \%$, while the $\Delta E$ s for the segmental motion of $\mathrm{P}(m-\mathrm{MS})$ and $\mathrm{P}(o$-MS $)$ are larger than that of the latter.

Bach et al. have shown that the transition temperatures for the model compounds of the methylderivatives of polystyrene, $o$-methylethylbenzene, $m$ methylethylbenzene, and $p$-methylethylbenzene, were 60,45 , and $40^{\circ} \mathrm{C}$, on the basis of the behavior of molar extinction coefficients as a function of temperature, and that the transition phenomena of these compounds involved the conformational changes concerning the rotation of the phenyl ring about the $\mathrm{C}_{\mathrm{arom}}-\mathrm{C}_{\mathrm{aliph}}$ bond. ${ }^{2}$ The temperature region of the transition phenomena in the methyl-substituted polystyrenes is similar to that in the model compounds, and so it is considered that the activation energy of G-motion in Table II is the difference of the conformational energy between the most stable and the most unstable position of the phenyl ring. By analogy with the conformations of the central ring in 2,4,6-triphenylheptane, ${ }^{2}$ the most probable positions of phenyl ring in $\mathrm{P}(o-\mathrm{MS})$ are shown in Figure 9. Taking into account the steric hindrance between the methyl group and the backbone, it seems reasonable

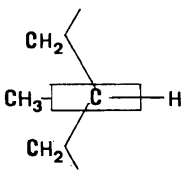

(I)

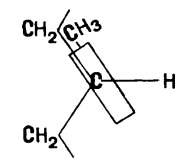

(III)

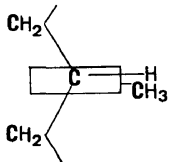

(II)

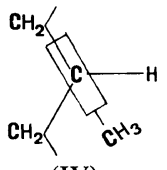

(IV)
Figure 9. Most probable positions of phenyl rings in $\mathrm{P}(o$-MS).

that the most stable conformer is I and that the most unstable conformer is III. The same interpretation can be proposed for $\mathrm{P}(m-\mathrm{MS})$ and $\mathrm{P}(p-\mathrm{MS})$, and it seems that the degree of the steric hindrance effect between the methyl group and the backbone determines the trends of the activation energy for the G-motion in Table II.

\section{REFERENCES}

1. J. B. Helms and G. Challa, J. Polym. Sci, $A-2, \mathbf{1 0}$, 1447 (1972).

2. N.-L. Bach Van, C. Noel, and L. Monnerie, J. Polym. Sci., Polym. Symp., No. 52, 283 (1975).

3. Y. Inoue and T. Konno, Polym. J., 8, 457 (1976).

4. F. Laupretre, C. NOEL, AND L. Monnerie, $J$. Polym. Sci., Polym. Phys. Ed., 15, 2127 (1977).

5. F. Laupretre, C. Noel, and L. Monnerie, J. Polym. Sci., Polym. Phys. Ed., 15, 2143 (1977).

6. D. C. Evance, L. Phillips, J. A. Borrie, and M. H. George, J. Polym. Sci., Polym. Lett., 12, 199 (1974).

7. D. M. Doddell, V. Glushke, and A. Allerhand, $J$. Chem. Phys., 56, 3683 (1972).

8. J. Schaefer and D. F. S. Natusch, Macromolecules, 5, 416 (1972).

9. K. H Kuhlman and . M. Grant, J. Chem. Phys., 55, 2998 (1971).

10. A. Allerhand, D. Doddrell, and R. Komoroski, J. Chem. Phys., 55, 189 (1971). 